\title{
Rationing in health systems: A critical review
}

\author{
Iman Keliddar ${ }^{1}$, Ali Mohammad Mosadeghrad ${ }^{2 *}$, Mehdi Jafari-Sirizi ${ }^{3}$
}

Received: 20 Jan 2017

Published: 27 Aug 2017

\begin{abstract}
Background: It is difficult to provide health care services to all those in need of such services due to limited resources and unlimited demands. Thus, priority setting and rationing have to be applied. This study aimed at critically examining the concept of rationing in health sector and identifying its purposes, influencing factors, mechanisms, and outcomes.

Methods: The critical interpretive synthesis methodology was used in this study. PubMed, Cochrane, and Proquest databases were searched using the related key words to find related documents published between 1970 and 2015. In total, 161 published reports were reviewed and included in the study. Thematic content analysis was applied for data analysis.

Results: Health services rationing means restricting the access of some people to useful or potentially useful health services due to budgetary limitation. The inherent features of the health market and health services, limited resources, and unlimited needs necessitate health services rationing. Rationing can be applied in 4 levels: health care policy- makers, health care managers, health care providers, and patients. Health care rationing can be accomplished through fixed budget, benefit package, payment mechanisms, queuing, copayments, and deductibles.

Conclusion: This paper enriched our understanding of health services rationing and its mechanisms at various levels and contributed to the literature by broadly conceptualizing health services rationing.
\end{abstract}

Keywords: Health system, Health Care Rationing, Health resources, Patient selection, Critical review

Copyright $@$ Iran University of Medical Sciences

Cite this article as: Keliddar I, Mosadeghrad AM, Jafari Sirizi M. Rationing in health systems: A critical review. Med J Islam Repub Iran. 2017 (27 Aug);31:47. https://doi.org/10.14196/mjiri.31.47

\section{Introduction}

The World Health Organization defined health as a state of complete physical, mental, and social well-being and not merely the absence of disease or infirmity (1). Accordingly, governments should establish robust health systems to promote the health status of their nations. Every human being has the right to have access to the highest attainable standards of health without distinction of gender, race, religion, belief, income, or social class (1). Providing high quality, accessible, and affordable health services should be the main goal of health care organizations (2).

Health care organizations are facing several challenges such as unlimited demands, increasing costs, and resource shortage (3-4). During the last 15 years, the rate of health expenditure growth exceeded the rate of economic growth (5). However, money, especially in developing countries,

Corresponding author: Dr Ali Mohammad Mosadeghrad, mosadeghrad@tums.ac.ir

1. Tehran University of Medical Sciences, Tehran, Iran.

2. School of Public Health, Tehran University of Medical Sciences, Tehran, Iran.

3. School of Health Management and Information Sciences, Iran University of Medical Sciences, Tehran, Iran. is disproportionately spent on those health services that have a low impact on people's health, and mainly benefit the rich (6). Inefficiencies in the delivery of health care services, variable providers' payment systems, supplier induced demand, and inappropriate use of expensive technologies are the main causes of escalating health care costs (7). For instance, in some OECD countries, and the US, new advanced technologies with less marginal effectiveness were sometimes used instead of alternative and less expensive existing procedures (8). Redirecting even a fraction of that money could expand useful health care coverage, enhance quality of care, and improve patient satisfaction.

It is highly important to get the best value for money due to the shortage of health care resources. Thus, health

$\uparrow$ What is "already known" in this topic:

Despite the importance of rationing in the health sector as a prerequisite to universal health coverage, there is little consensus about its meaning and practical mechanisms in the literature.

$\rightarrow$ What this article adds:

This study further developed the concept and theory of health services rationing through identifying its purposes, influencing factors, mechanisms, and outcomes. Furthermore, a systemic model of rationing in health systems was developed. 
Table 1. Criteria for quality appraisal of the papers

- Are the research goals and objectives clearly specified?

- Is the research design clearly specified and is it suitable for achieving research goals?

- Is the research process clearly explained?

- Are enough data displayed to support research interpretations and conclusions?

- Is the analysis method appropriate and adequately explained?

Source: Dixon-Woods, et al. 2006

care policy makers and administrators have to apply strategies like priority setting and rationing and should invest more in affordable, effective, patient-centered, and safe services that deliver the best health outcomes (9). Particularly, the situation worsens for health care organizations during the economic recession and public spending cuts.

The World Health Organization (2013) highlighted the importance of rationing as a prerequisite to universal health coverage (10). Despite the importance of rationing in health systems for universal health coverage, there is little consensus about its meaning and applied mechanisms in the literature. This study aimed at critically examining the concept and theory of health services rationing to contribute to a better understanding of its concept and related policy issues by addressing some key questions such as "what is health services rationing?", and "why, how and by whom are health services rationed?" We also provided a brief overview of the development of rationing concept in health sector and some of its policy implications.

\section{Methods}

Health care rationing literature is large, complex, and diverse. Thus, we decided to use critical interpretive synthesis (CIS), instead of conventional systematic review methodology, to achieve the aims of this study. Critical interpretive synthesis enables researchers to critically synthesize a diverse body of evidences and studies in a given field and generate theories. While conventional systematic review aims to test theories through searching for, appraising, and synthesizing the findings of the primary studies (aggregative syntheses) in a fixed procedure of predefined sequence, critical interpretive synthesis aims to generate a theory by including many different forms of evidence (Interpretive syntheses) through iterative, dynamic, interactive, and recursive processes of question formulation, searching for, data extraction, critique, and synthesis (11).

In this review, which was conducted during the summer of 2015, PubMed, Cochrane, and Proquest databases were searched to find published English literature in health services rationing from 1970 to 2015 . Keywords were rationing health*, priority setting health *, setting priority* and health*, using a combination of Medline subject headings (Mesh) and text words (tw). The reference lists of the retrieved articles were also reviewed for finding additional studies.

A data extraction form was developed according to the main objectives of the study to examine the concept and theory of rationing in the health sector and its purposes, influencing factors, processes, mechanisms, and outcomes. All retrieved studies were initially screened on title and abstract by one of the study members (IK). Relevance and contribution to theory development were the main criteria for appraising the quality of the papers in the interpretive review (12). Only fatally flawed papers were excluded using the criteria stated in Table 1 . The retrieved articles were reviewed critically and categorized using the data extraction form. Justification about each selected papers was done by consensus.

\section{Results}

In this study, 11668 records were retrieved, of which 8097 were excluded by title/abstract screening. After retrieving the full texts, we found that 161 studies met the quality appraisal criteria. Studies were conducted in a wide range of countries, and most of the studies were done in developed countries in Europe and America.

The synthesis of the literature was organized into 6 sections. In the first and second sections, the concept of rationing and its necessity in health sector were discussed. The third part was devoted to the trends of rationing in the health sector. Then, the levels of applying health care rationing were examined. Finally, the mechanisms for rationing health services were described.

\section{What is health services rationing?}

There is no universal definition of the word 'rationing'. Fourteen definitions of rationing were elicited from the literature (Table 2). The word 'rationing' has derived from the Latin 'ration', meaning 'to apply limitation in usage' (13). In economics, rationing refers to controlling the distribution of scarce resources and services among a population (14). Oxford Dictionary defines rationing as 'allowing each person to have only a fixed amount of a commodity' (15).

Ubel defines rationing as "any implicit or explicit mechanisms that allow people to go without beneficial services" (16). Russell (2002) defined rationing as "someone or some institution's deliberate decision to distribute a scarce good among competing persons" (17). According to Brown (1991), rationing is the "deliberate and systematic withholding of beneficial goods or services from some elements of the population on the grounds that the society cannot afford to extend them" (18).

Scarcity, resource constraint, and exclusion are $3 \mathrm{im}-$ portant notions that constitute the definition of health care rationing. Therefore, we define health services rationing as "restricting the access of some people to useful or potentially useful health services due to budgetary limitation".

\section{Why health services must be rationed?}

Products or services should have 3 features to be rationed. These features are scarcity, value, and controllability (17). All these features are inherent in health care services, which make rationing a necessity. First, health care 
Table 2. The Definitions of Health Services Rationing

\begin{tabular}{|c|c|}
\hline Author (s) & Definition \\
\hline Aaron and Schwartz (1990) & $\begin{array}{l}\text { "The deliberate and systematic denial of certain types of services, even when they are known to be beneficial, } \\
\text { because they are deemed too expensive." ( p.418) (19) }\end{array}$ \\
\hline Asch and Ubel (1997) & "Not to provide some beneficial health care services, which are simply too expensive" (p.1668) (20). \\
\hline Baily (2003) & $\begin{array}{l}\text { "To limit the beneficial health care an individual receives by any means - price or non-price, direct or indirect, } \\
\text { explicit or implicit" (p.35) (21). }\end{array}$ \\
\hline Bennett and Chanfreau (2005) & "The controlled distribution of scarce goods or services" (p. 542) (22). \\
\hline Brown (1991) & $\begin{array}{l}\text { "The deliberate, systematic withholding of beneficial goods or services from some elements of the population on } \\
\text { the grounds that society cannot afford to extend them."(p.30) (18) }\end{array}$ \\
\hline Dougherty (1991) & $\begin{array}{l}\text { "The denial of services that are potentially beneficial to some people because of limitations on the resources avail- } \\
\text { able for health care" (p.3) (23) }\end{array}$ \\
\hline Goldbeck-Wood (1997) & "Withholding a beneficial treatment because of its costs" (p.146 ) (24) \\
\hline Fleck (1992) & "The denial of life-sustaining medical care on the basis of an arbitrary budgetary limit" (p.1605) (25). \\
\hline Hadorn and Brook (1991) & $\begin{array}{l}\text { "The withholding of necessary services and societal toleration of inequitable access (for example, based on ability } \\
\text { to pay) to services acknowledged being necessary by reference to necessary care guidelines." (p.3331) (26) }\end{array}$ \\
\hline Hurst and Danis (2007) & "Any clinical decision to place or to accept a limit on benefits for a patient" (p.248) (27) \\
\hline Maynard (1999) & $\begin{array}{l}\text { "An individual is deprived of care which is of benefit (in improving health status, or the length and quality of life), } \\
\text { which is desired by the patient." (p.6) (28) }\end{array}$ \\
\hline Ole Frithjof (1999) & $\begin{array}{l}\text { "The withholding of potentially beneficial health care through financial or organizational features of the health } \\
\text { care system in question." (p.1426) (29) }\end{array}$ \\
\hline Pickard and Sheaff (1999) & "Restricting access to health care for nonclinical reasons such as cost control" (p.38) (30). \\
\hline Ubel (2001) & "Any implicit or explicit mechanism that allows people to go without beneficial services" (p.35) (16). \\
\hline
\end{tabular}

is a scarce commodity. The resource shortage for health services delivery is especially noticeable in the developing countries, where a smaller share of resources is allocated to the health sector (31). The problem would be worse during the economic recession. For instance, health spending fell in half of the EU countries between 2009 and 2012, following the economic crisis. As a result, health expenditure declined by $0.6 \%$ annually, compared with an annual growth of $4.7 \%$ between 2000 and 2009 (32). In addition, the human resources needed for health care organizations are decreasing due to the aging societies and a rise in the demand for health care services in Europe (33).

Second, health is a valuable good and has the value of life principle; and life itself is inseparable from health. Without some degree of healthy functionality, the living whole would not exist. Thus, people may have the willingness to give their assets away in return of getting their health back. Thus, access to adequate health care is considered as a fundamental human right in many countries. Finally, the health services are controllable and can be refused to provide to some people and reserved to meet more urgent and immediate demands. Therefore, health service is one of the cases which demands rationing.

The goal of rationing is to supply rational, equitable, and cost-effective health services while reducing expenditure (34). Moreover, the inherent characteristics of the health market also make it necessary to apply rationing (Table 3). Characteristics such as information asymmetry and heterogeneity make the use of rationing inevitable. The information asymmetry between patients and physicians may increase supplier induced demand (35). On the other hand, health care professionals deliver the services to patients differently $(36,37)$. Variations in medical practices raise questions about the equity, quality, and efficiency of health care services (38). Limited health care resources suggest applying rationing mechanisms such as evidence-based guidelines and protocols to deliver just effective care to patients. As a result, induced demand and medical practice variations can be reduced.

\section{What is the trend of health services rationing?}

The notion of rationing has evolved gradually from an "implicit" and "hidden nonsystematic" to an "explicit and open systematic" mode (39). Implicit rationing relies on hidden norms and rules mainly defined by health care providers such as physicians. In contrast, explicit rationing is based on clearly defined indicators such as patient age, gender, financial status, and clinical condition.

Traditionally, an individual or groups of doctors decide about who and when gets treated in an uncoordinated way (40). The public is not involved in the rationing decisions in a "hidden nonsystematic approach. Hence, medical doctors within the given budget limit, allocate resources based on clinical priorities and inter-specialty bargaining power. For instance, they may deny dialysis to patients over the age of 55 years according to an unwritten rule due to limited budgets.

In the 1980 s, rationing decisions were started to carry out according to systematic well-defined efficiency considerations. The aim was to maximize the amount of health for a population for a given budget without involving the public in the rationing decisions (41). Doctors had a limited power in determining rationing principles and their applications in practice. Using relatively high de-

\begin{tabular}{ll} 
Table 3. Determinants of rationing health services \\
\hline Determinants of rationing & \multicolumn{1}{c}{ Features } \\
\hline Characteristics of health services & $\bullet$ Value of health services \\
& $\bullet$ Scarcity of health services \\
& $\bullet$ Controllability of health services \\
Characteristics of health market & $\bullet$ Information asymmetry \\
& $\bullet$ Heterogeneity \\
\hline
\end{tabular}


ductibles and copayments to discourage people from using expensive health services is an example of hidden systematic rationing.

Finally, open systematic rationing has been used since 1990s in some developed countries such as UK (42), where a public recognition was happening. In some countries, a minimum health care package was introduced to ensure people's access to those services, and health services outside of this package were not guaranteed to the population.

\section{Who does health services rationing?}

Health services rationing decisions could be taken by various organizations, groups, and individuals in different levels of a health system. Mechanic (1997) argues that decisions about health services rationing are normally made at 3 levels: health systems, intermediate, and clinical levels (34). At the health care systems level, governments, health authorities, or health insurance companies determine the total health care spending levels, the types of health services to be covered, the extent of technological development, the location of health care facilities, and the extent of patient cost sharing. At the intermediate level, subunits such as hospitals determine the number and mix of various providers, the extent of direct access, schedules, and waiting times for various health care services. Finally, at the clinical level, clinicians decide about treatment priorities considering types of patients, varying conditions, and treatment approaches.

Krizova and Simek (2002) believe that rationing occurs at political and clinical levels (43). Health care politicians, health insurance companies, and hospital executives set up an external economic framework for clinical work. At the clinical level, physicians and medical professionals are responsible for quality of care and carry out the rationing. Klein (1997) suggests that rationing could occur at macro, meso- and micro- levels (44). The macro- level rationing refers to decisions about how much funding should be allocated to health services altogether. Allocation of resources between particular services and localities occur at the meso- level. Finally, rationing at the micro- level deals with decisions on treating individual patients. Coast et al. (1996) propose 4 levels for rationing health services: (a) across whole services, (b) across treatments within services, (c) within treatments, and (d) between individual patients (45).

Therefore, considering the complex nature of health care organizations, rationing could be practiced at 4 levels: patient, provider, manager, and policymaker (Fig. 1). The individual patient's needs and preferences may lead to self-rationing. A sick person without a health insurance plan makes the decision to seek care by comparing the costs and benefits of receiving the care. S/he might refuse

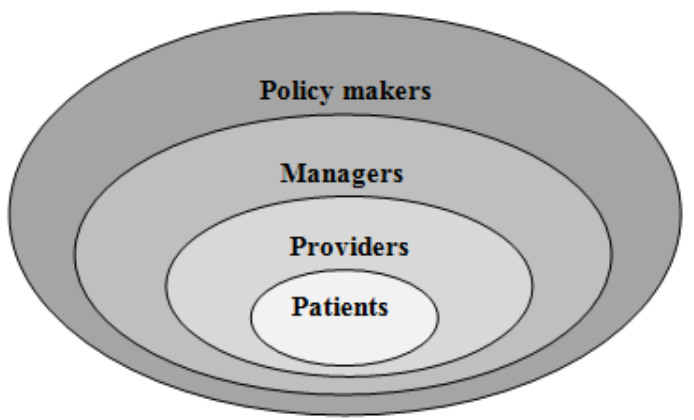

Fig. 1. Health system rationing levels

to proceed to get the services if could not afford it or see the costs more than the benefits. Price-based self-rationing leads to underutilization of health care services. The health care team consists of the individual physicians and care providers. Basically, rationing decisions are made according to the clinical interactions between physicians and patients. Despite a commitment to ration health care services openly in theory, clinicians use more implicit methods in practice.

The third level of the health services rationing occurs at the organizational level (e.g, hospital, clinic, and nursing home) that provide infrastructure and needed resources to support health care providers. Managers are responsible for allocating resources among various health care providers and may ration some health services.

Finally, politicians, policymakers and health insurance companies at the macro- level set some rules and regulations about the allocated health care budget, services coverage, and cost sharing mechanisms considering political, economic, social, and technological factors. The comparison between different levels of health services rationing proposed by different scholars and this study is demonstrated in Table 4.

Health care rationing also depends on the financing sources of a health system. While in tax-based health systems, the government authorities could keep the responsibility for health care rationing, in payroll and premiumbased health systems, social or private insurance companies deal with the responsibility. Finally, in an out of pocket-based health system, health care institutes' managers, clinicians, and even patients themselves make the decisions for rationing health care services.

Rationing can be applied in all 4 functions of the health systems including governance, financing, resource generation, and health services provision. At the macro- level, politicians and health care authorities, as the stewards of the national resources, plan and direct rationing health care services to establish the fairest possible health system, to make the best possible use of limited resources,

Table 4. Levels of Health Services Rationing in Health Systems

\begin{tabular}{ccccc}
\hline Klein (1992) & Mechanic (1997) & Krizova \& Simek (2002) & Coast et al. (1996) & This study \\
\hline Macro level & Health care system level & Political level & Across whole services & Policy makers \\
Meso level & Intermediate level & - & Across whole services, Across treatments within services & Managers \\
& & & & \\
Micro level & Clinical level & Clinical level & Within treatments, Between individual patients & Providers \\
- & - & - & - & Patients \\
\hline
\end{tabular}


and to deliver the best health outcomes. The government and Ministry of Health should regulate and balance rationing at meso- and micro- levels to maximize the probability of success in health services rationing. A lack of rationing health care services policy at the political level may lead to uncontrolled medical professionals' power of decisionmaking.

\section{How do ration health services?}

Health is a right and health services should be equitably accessible to all. Thus, health care services should be rationally distributed to fit the needs of the people who need them. To do so, it is sometimes necessary to limit the access of less needy people to some health care services to provide them to more urgent needs. Several mechanisms could be used for health care rationing, which is classified as supply and demand side mechanisms.

Policymakers and authorities at macro- level can use methods such as budget, benefit package, and payment mechanisms to control the behavior of health care managers and providers and restrict providing a broad variety of inappropriate health services. Budget influences the behavior of providers and leads them to reallocate health care resources or even ration some health care services. This method was used in the UK between the 1950s and early 1980s. Budget may even lead to covert rationing. For instance, tight budgets in the UK resulted in the denial of dialysis and some forms of heart surgery to patients over the age of 55 years (5).

Health services coverage is sometimes limited through the specification of a menu of core health care services (minimum health care package) to be made available for the public. Accordingly, certain health care services outside of this package will be unavailable to all patients (46). Practitioners can use clinical guidelines for requesting appropriate effective health care services for patients. Clinical guidelines assist practitioners on which diagnostic tests to order, how to provide surgical, medical, and nursing services and how long patients should stay in the hospital (47). In addition, policymakers use cost-benefit and cost-effectiveness analyses to finalize the benefit package (minimum health care package).

Payment mechanisms as incentives influence the behavior of health care professionals to decrease or increase the number of patients (through capitation), the number of visits (through salary or fee-for-service), the type and quality of services (through fee for services), and the referral of patients to other health care facilities (through salary, fee-for-service) (48).

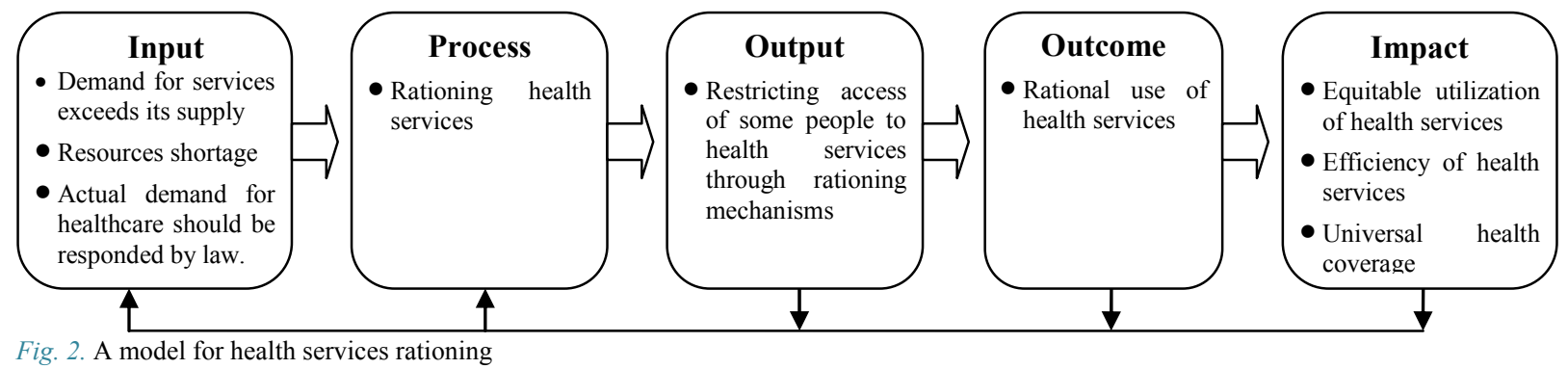


and feedback. At the first step, a condition occurs in which the demand exceeds the supply of health resources. This gap is made due to a pressure of the environment. The resource shortages and the right to high quality and affordable health services (inputs) feed into the rationing system. Therefore, health system stewardship decides to restrict some people to access health services (process), and this is done through using demand-side and supplyside rationing strategies (outputs). Rationing health services leads to rational utilization of health services (outcome). The impact of health services rationing depends on its effects on the equity of health and efficiency of health services. The information about reactions to health services rationing performance in each stage should be used for improvement.

The methodology of this study benefits from the comprehensiveness and theory generated nature. The product of the synthesis is not aggregations of data, but a theory grounded in the studies included in the review. The final proposed conceptual model breaks down the whole picture of rationing in the health system into discrete stages. The model can be applied to all health systems. However, this study had a limitation. The model placed too little emphasis on what is happening inside the health services rationing process at micro- levels, and it just provided a big picture of health care rationing at the macro- level of a health system.

\section{Conclusion}

Developing countries such as Iran face serious challenges in the limited resources and unlimited needs. These issues affect the effectiveness, efficiency, and equity of health care services provided to the society. This paper helps policymakers and managers understand the necessity of health services rationing and its mechanisms at various levels. Health services rationing could improve the utilization of health services and move toward universal health coverage. The stewardship of the health care system should regulate and balance rationing to control the behavior of the managers, health care providers (supplyside- rationing), and patients (demand- side- rationing).

\section{Acknowledgements}

This study was part of a $\mathrm{PhD}$ thesis supported by Tehran University of Medical Sciences (TUMS). The authors would like to thank the anonymous reviewers for their valuable comments on the earlier draft of the paper.

\section{Conflict of Interests}

The authors declare that they have no competing interests.

\section{References}

1. World Health Organization. Constitution of the World Health Organization. Geneva: World Health Organization; 2006.

2. Mosadeghrad AM. Essentials of total quality management in health care: a systematic review. Int J Health Care Qual Assur. 2014; 27(6):544-58.

3. Mosadeghrad AM. Why TQM does not work in Iranian health care organisations. Int J Health Care Qual Assur. 2014;27(4):320-35.

4. Mosadeghrad AM. Why TQM programs fail? A pathology approach.
TQMJ. 2014;26(2):160-87.

5. Callahan D. Rationing: Theory, Politics, and Passions. The Hastings Center Report. 2011;41(2):23-7.

6. James C, Carrin G, Savedoff W, Hanvoravongchai P. Clarifying Efficiency-Equity Tradeoffs Through Explicit Criteria, With a Focus on Developing Countries. Health Care Analysis: HCA. 2005;13(1):3351 .

7. Mosadeghrad AM. Essentials of health care organisation and management, Tehran: Dibagran Tehran; 2015.

8. Berwick DM, Hackbarth AD. Eliminating waste in US health care. Jama. 2012;307(14):1513-6.

9. Sorenson C, Drummond M, Kanavos P. Ensuring Value for Money in Health Care: The Role of Health Technology Assessment in the European Union: World Health Organization; 2008.

10. World Health Organization. Health Systems Financing: The Path to Universal Coverage: World Health Organization; 2010.

11. Dixon-Woods M, Cavers D, Agarwal S, Annandale E, Arthur A, Harvey J, et al. Conducting a critical interpretive synthesis of the literature on access to health care by vulnerable groups. BMC Med Res Method. 2006;6(1):35.

12. Gough D. Weight of evidence: a framework for the appraisal of the quality and relevance of evidence. Res Papers Educat. 2007;22(2):21328.

13. Merriam-Webster. Merriam-Webster's Collegiate Dictionary: Eleventh Edition: Merriam-Webster, Incorporated; 2004.

14. Coleman R. The Independent Medicare Advisory Committee: Death Panel or Smart Governing? Issues in Law \& Medicine. 2011;27(2):121-77.

15. Stevenson A. Oxford Dictionary of English: OUP Oxford; 2010.

16. Ubel PA. Pricing Life: Why It's Time for Health Care Rationing: MIT Press; 2001

17. Russell BJ. Health-care rationing: Critical features, ordinary language, and meaning. The Journal of Law, Medicine \& Ethics. 2002;30(1):82-7.

18. Brown LD. The national politics of Oregon's rationing plan. Health affairs. 1991;10(2):28-51.

19. Aaron H, Schwartz WB. Rationing Health Care: The Choice Before Us. Science. 1990;247(4941):418.

20. Asch DA, Ubel PA. Rationing by any other name. The New England Journal of Medicine. 1997;336(23):1668-71.

21. Baily MA. Managed care organizations and the rationing problem. The Hastings Center Report. 2003;33(1):34-42.

22. Bennett S, Chanfreau C. Approaches to rationing antiretroviral treatment: ethical and equity implications. World Health Organization Bulletin of the World Health Organization. 2005;83(7):541-7.

23. Dougherty CJ. Setting health care priorities. Hastings Center Report. 1991;21(3):1-10.

24. Goldbeck-Wood S. "Smart" rationing is possible. British Medical Journal. 1997;315(7101): 146 .

25. Fleck LM. Just health care rationing: A democratic decisionmaking approach. University of Pennsylvania Law Review. 1992:1597-636.

26. Hadorn DC, Brook RH. The health care resource allocation debate: defining our terms. JAMA. 1991;266(23):3328-31.

27. Hurst SA, Danis M. A Framework for Rationing by Clinical Judgment. Kennedy Institute of Ethics Journal. 2007;17(3):247-66.

28. Maynard A. Rationing health care: an exploration. Health Pol. 1999;49(1):5-11.

29. Ole Frithjof N. Health care rationing--are additional criteria needed for assessing evidence based clinical practice guidelines? British Medical Journal. 1999;319(7222):1426-9.

30. Pickard S, Sheaff R. Primary Care Groups and NHS Rationing: Implications of the Child B Case. Health Care Analysis: HCA. 1999;7(1):37-56.

31. Peters DH, Garg A, Bloom G, Walker DG, Brieger WR, Hafizur Rahman M. Poverty and access to health care in developing countries. Annals of the New York Academy of Sciences. 2008;1136(1):161-71.

32. OECD. Health at a Glance: Europe 2014: OECD Publishing; 2014. Available from: http://dx.doi.org/10.1787/health_glance_eur-2014-en.

33. Kuhlmann E, Groenewegen PP, Batenburg R, Larsen C. Health Human Resources Policy in Europe. In: Kuhlmann E, Blank RH, Bourgeault IL, Wendt C, editors. The Palgrave International Handbook of Health care Policy and Governance. London: Palgrave Macmillan UK; 2015. p. 289-307.

34. Mechanic D. Muddling through elegantly: Finding the proper balance in rationing. Health Affairs. 1997;16(5):83-92. 
35. Mosadeghrad AM. A conceptual framework for quality of care. Mat Soc Med. 2012; 24(4): 251-261.

36. Mosadeghrad AM. Factors Affecting Medical Service Quality. Iranian Journal of Public Health. 2014;43(2):210-220.

37. Mosadeghrad AM. Factors influencing health care service quality. International Journal of Health Policy and Management. 2014;3(2): 77-89.

38. Corallo AN, Croxford R, Goodman DC, Bryan EL, Srivastava D, Stukel TA. A systematic review of medical practice variation in OECD countries. Health Policy. 2014;114(1):5-14.

39. Obermann K, Buck DJ. The health care rationing debate: more clarity by separating the issues? HEPAC. 2001;2(3):113-7.

40. Strosberg MA, Wiener JM, Baker R, Institution B. Rationing America's Medical Care: The Oregon Plan and Beyond: Brookings Institution; 1992.

41. Williams A. Cost-effectiveness analysis: is it ethical? Journal of Medical Ethics. 1992;18(1):7-11.

42. Dean M. london Rationing gets official seal of approval from UK Health Secretary. The Lancet. 2000;355(9197):49.

43. Krizova E, \& Simek J. Rationing of expensive medical care in a transition country-nihil novum? Journal of Medical Ethics. 2002;28(5):308-12.

44. Klein R. The rationing debate: Defining a package of health care services the NHS is responsible for the case for. British Medical Journal. 1997;314(7079):506-9.

45. Coast J, Donovan J, \& Frankel S. Priority setting: the health care debate: J. Wiley; 1996.

46. Syrett K. Law, Legitimacy and the Rationing of Health Care: A Contextual and Comparative Perspective: Cambridge University Press; 2007.

47. Woolf SH, Grol R, Hutchinson A, Eccles M, Grimshaw J. Potential benefits, limitations, and harms of clinical guidelines. British Medical Journal. 1999;318(7182):527.

48. Gröne $\mathrm{O}$, Garcia-Barbero M. Integrated care. International journal of integrated care. $2001 ; 1(2)$

49. Arnesen KE, Erikssen J, Stavem K. Gender and socioeconomic status as determinants of waiting time for inpatient surgery in a system with implicit queue management. Health Policy. 2002;62(3):329-41.

50. World Health Organization. The World Health Report 2000: Health Systems: Improving Performance. Geneva: World Health Organization; 2000. 